\title{
Edgar Quinet, une conscience européenne, dir. S. GUERMÈs et B. KRULIC
}

\section{Tatiana Antolini-Dumas}

\section{(2) OpenEdition}

\section{Journals}

\section{Édition électronique}

URL : https://journals.openedition.org/studifrancesi/45284

DOI : 10.4000/studifrancesi.45284

ISSN : 2427-5856

Éditeur

Rosenberg \& Sellier

\section{Édition imprimée}

Date de publication : 1 août 2021

Pagination : 389-390

ISSN : 0039-2944

\section{Référence électronique}

Tatiana Antolini-Dumas, "Edgar Quinet, une conscience européenne, dir. S. GUERMĖs et B. KRULIC », Studi Francesi [En ligne], 194 (LXV | II) | 2021, mis en ligne le 01 septembre 2021, consulté le 15 octobre 2022. URL : http://journals.openedition.org/studifrancesi/45284 ; DOI : https://doi.org/10.4000/ studifrancesi.45284

Ce document a été généré automatiquement le 15 octobre 2022

\section{(c) (i) (9)}

Creative Commons - Attribution - Pas d'Utilisation Commerciale - Pas de Modification 4.0 International - CC BY-NC-ND 4.0

https://creativecommons.org/licenses/by-nc-nd/4.0/ 


\title{
Edgar Quinet, une conscience européenne, dir. S. GUERMÈs et B. KRULIC
}

\author{
Tatiana Antolini-Dumas
}

\section{RÉFÉRENCE}

Edgar Quinet, une conscience européenne, dir. S. GUERMÈs et B. KRULIC, Peter Lang, 2018, 276 pp.

1 Les seize contributions figurant dans ce recueil sont issues du colloque qui s'est tenu à la Fondation Singer-Polignac en mars 2017. Donnant un aperçu de la pensée multiforme d'Edgar Quinet, elles permettent de mesurer son influence auprès de ses contemporains et offrent un panorama passionnant de l'Europe issue du Congrès de Vienne.

Dans la présentation générale, Sophie GUERMÈs et Brigitte KRULIC resituent la genèse de sa réflexion dans son contexte historique et biographique: l'écrivain a vécu en Allemagne, à Bruxelles, il a épousé une Allemande, s'est remarié avec une Roumaine. Il voit la Grèce accéder à l'Indépendance, il soutient les partisans du Risorgimento; ami de Mickiewicz, il se préoccupe du sort de la Pologne... Penseur du théologico-politique, historiographe de la Révolution française, ayant réfléchi à ce qui fonde le génie des peuples, il s'enthousiasme pour les processus démocratiques qui voient alors le jour. Il se fait le chantre des peuples qui, en Europe, aspirent à leur propre souveraineté et appelle de ses vœux une Europe solidaire. Son œuvre sous-tendue par une constante préoccupation morale est celle d'un idéaliste lucide.

3 La Révolution avec ses promesses de liberté constitue un des axes majeurs de la pensée de Quinet. Simone BERNARD-GRIFFITHS (La Révolution française et l'Europe jusqu'à la mort de Louis XVI dans "La Révolution" (1865) d'Edgar Quinet, pp.19-36) explique que pour l'écrivain, contraint à l'exil, le fait de penser la Révolution française dans ses relations avec les nations européennes permet de comprendre en partie l'échec politique et 
religieux de cette dernière. Éric FRANCALANZA (Quinet et la pensée des Lumières, pp. 37-59) s'attache à l'origine de sa pensée. Fondé sur l'universalité des valeurs, dépassant les clivages et les frontières, résolvant les oppositions historiques, politiques et religieuses, l'esprit des philosophes du XviII ${ }^{e}$ siècle a nourri la conscience européenne de Quinet.

L'article de Loris CHAVANETTE (Un héros européen: Napoléon l'audacieux vu par Quinet, pp. 61-76) examine la fascination de Quinet pour Bonaparte, «bouclier de la civilisation moderne contre la vieille Europe monarchique»(p.67), puis son aversion pour l'Empereur et met également en évidence les contradictions qui apparaissent dans ses écrits de maturité. Vicente ROMERo ESPINOza (La Déchirure du Printemps des peuples, pp. 77-90) évoque la participation du Chilien, Francisco Bilbao, et celle de Quinet aux journées révolutionnaires de juin 1848. Défendant la République, Quinet, alors colonel de la onzième Légion de la Garde nationale, fait partie des corps armés chargés de protéger le Palais du Luxembourg. Actif pendant les deux premières journées, il fait néanmoins preuve de modération dans les combats contre les ouvriers insurgés et tempère la violence des vainqueurs.

5 La suite du volume est consacrée à sa connaissance de l'étranger. Si la contribution de Marie-France воRот (Entre lucidité et cécité: les vacances en Espagne du professeur Quinet, pp.91-107) rend compte de l'acuité de son regard sur les mœurs et la vie politique espagnole, elle signale en outre l'importance des références littéraires qui ont informé sa représentation de l'Espagne. Tatiana ANTOLINI-DumAs (L'Espagne d'Edgar Quinet, pp. 109-122) s'intéresse aux tensions qui constituent, selon Quinet, le génie espagnol. Excellent connaisseur de l'Espagne, auteur d'un récit de voyage très original, l'écrivain oppose aux valeurs chevaleresques héritées du Romancero, à la résistance héroïque du peuple pendant la guerre d'Indépendance, à la corrida, rite archaïque à dimension politique, l'attachement regrettable des Espagnols au catholicisme et à la monarchie. Selon lui, le libéralisme modéré finit par confisquer la souveraineté du peuple et compromet le rôle que l'Espagne aurait pu jouer dans les processus d'émancipation démocratiques européens.

6 Irini apostolou (Quinet entre la Grèce et l'Orient, pp. 123-137) souligne l'importance de l'Expédition scientifique de Morée à laquelle Quinet participe en 1829 alors que la Grèce est en pleine révolution. Il accomplit à cette occasion un voyage dans le temps qui célèbre le passé glorieux de la Grèce et le relie à l'actualité du pays visité tout en défendant le droit des peuples à disposer d'eux-mêmes et en mentionnant les liens historiques qui unissaient l'Orient et l'Occident. Sandrine MAUFROY (Edgar Quinet, la Grèce et le philhellénisme, pp.139-155) analyse avec une grande minutie le philhellénisme atypique de Quinet. Tandis que fleurissent partout en Europe, des comités mobilisés en faveur des Grecs, Quinet profite de cet engouement pour partir. Ses raisons sont multiples: personnelles, scientifiques, philosophiques, poétiques. Ses écrits témoignent toujours d'une grande indépendance d'esprit; il porte un jugement très positif sur la façon de gouverner de Kapodistrias, il rend justice aux Grecs dont la misère l'a marqué et dénonce l'attitude de la Russie, de l'Angleterre, de l'Europe occidentale vis-à-vis d'elle.

7 Centrée sur l'Italie, la contribution de Sophie GUERMÈs (Quinet, le pape et le Risorgimento, pp. 229-241) montre comment s'élabore la réflexion historique et politique de Quinet. Manifestant son soutien au Risorgimento, l'écrivain célèbre le devenir d'une nation en voie d'affranchissement, mais il insiste sur le fait que l'Italie demeure une mosaïque qui peine à exister, en tant que nation à part entière, tant la papauté nuit au processus de 
son unification. Sa réflexion doit aussi se concevoir dans une perspective transnationale: l'écrivain n'exhorte pas seulement les Italiens à se libérer de toute entrave, Sophie Guermès rappelle que dans la mesure où le catholicisme est pour Quinet «un obstacle à toute constitution solide de l'Europe» (p. 229) la France se doit de diffuser son modèle et de jouer un rôle fondamental dans l'émancipation des peuples opprimés.

Catherine DURANDIN (Edgar Quinet et les Roumains, pp. 157-168) constate, en revanche, que sa conception de la Roumanie n'échappe pas aux contradictions et aux stéréotypes qui étaient alors de mise, notamment dans le milieu franco-roumain. Quinet, solidaire, mais marqué par l'exil et le deuil, défend la cause d'une nation souffrante qui s'achemine vers la liberté et l'indépendance.

Spécialiste de l'Europe méridionale, Quinet connaît néanmoins très bien l'Allemagne. Brigitte KRULIC (Edgar Quinet et l'unité allemande, pp. 183-193) souligne la pertinence de ses analyses: il met en garde ses contemporains contre l'unité allemande qu'il voit poindre après des siècles d'affaiblissement politique. En effet, Quinet comprend très tôt qu'en raison des frustrations nées du Congrès de Vienne, la nation allemande s'est construite de manière à combattre les modèles culturels français. Après Sadowa, l'unité allemande se réalise au mépris des valeurs universelles et démocratiques de la France républicaine. Incapable de surmonter son ressentiment, l'Allemagne prussienne se referme sur elle-même, et privilégie la force au détriment du droit.

10 L'influence de Quinet dépasse les frontières de l'Europe. Arlenice ALMEIDA DA SILVA (Edgar Quinet et le romantisme brésilien, pp. 169-181) démontre que l'auteur d'Ahasvérus était bien connu des principaux poètes romantiques brésiliens: c'est le cas de Castro Alves, fervent républicain, le poète des esclaves. Mais lorsque Quinet salue l'Amérique comme un espace de liberté, un peu abstrait, Castro Alves insiste bien davantage sur la souffrance concrète du peuple, sur l'esclavage notamment, tragédie aberrante et inacceptable qui ne prit fin au Brésil qu'en 1888.

11 Il faut, pour approcher la pensée de Quinet, prendre aussi en considération l'histoire des idées, le jeu des influences et des échanges littéraires et intellectuels transnationaux. Ainsi, Christophe Bouton (La Chaîne du passé, pp. 195-214) analyse ce que la philosophie de l'histoire de Quinet doit à la pensée de Herder qu'il traduit en 1827, puis à celle d'Hegel, découvert à travers Victor Cousin. Dès les années 1825, Quinet a lu et annoté l'Essai sur l'esprit et l'influence de la Réformation de Luther de Villers. Michèle Moulin (Edgar Quinet et l'héritage de Charles de Villers, pp. 243-261) examine l'influence de cet ouvrage et traite, ce faisant, de la question essentielle du protestantisme de Quinet: une religion de liberté aux antipodes d'un catholicisme perçu comme l'instrument de la servitude des peuples.

12 L'article de Tomasz SZYMAŃSKI (Quinet, Mickiewicz et l'idée de religion universelle, pp. 215-228) évoque les relations de Quinet et de Mickiewicz, le cercle towianiste, leur conception d'une religion universelle, leur célébration d'individus providentiels tels que le Christ ou Napoléon, et examine également les causes de leur éloignement progressif. Fanny GRIBENSKI et Étienne JARDIN ("Le Souvenir des âmes heureuses", pp. 263-276) concluent le recueil en brossant le portrait d'un Quinet violoniste, interprétant Mozart et Viotti.

13 Contribuant à la reconnaissance de ce témoin d'exception, polyglotte, poète, philosophe, historien, homme d'action, voyageur et professeur, les études 
interdisciplinaires réunies ici par Sophie Guermès et Brigitte Krulic montrent que la conscience européenne de Quinet s'est nourrie de références littéraires, théologiques et philosophiques précises ainsi que d'échanges avec un grand nombre d'écrivains, de penseurs et de personnalités politiques. Le volume ne retiendra pas seulement l'attention des spécialistes de Quinet, il captivera tout particulièrement les comparatistes, les historiens et les chercheurs qui s'intéressent à la circulation des idées et des représentations dans une perspective transnationale. 